This item was submitted to Loughborough's Research Repository by the author.

Items in Figshare are protected by copyright, with all rights reserved, unless otherwise indicated.

\title{
Infection outbreaks in acute hospitals: a systems approach
}

PLEASE CITE THE PUBLISHED VERSION

PUBLISHER

Sage [on behalf of Infection Prevention Society (๑ The Author)]

VERSION

SMUR (Submitted Manuscript Under Review)

LICENCE

CC BY-NC-ND 4.0

REPOSITORY RECORD

Waterson, Patrick. 2019. "Infection Outbreaks in Acute Hospitals: A Systems Approach". figshare. https://hdl.handle.net/2134/7619. 
This item was submitted to Loughborough's Institutional Repository (https://dspace.lboro.ac.uk/) by the author and is made available under the following Creative Commons Licence conditions.

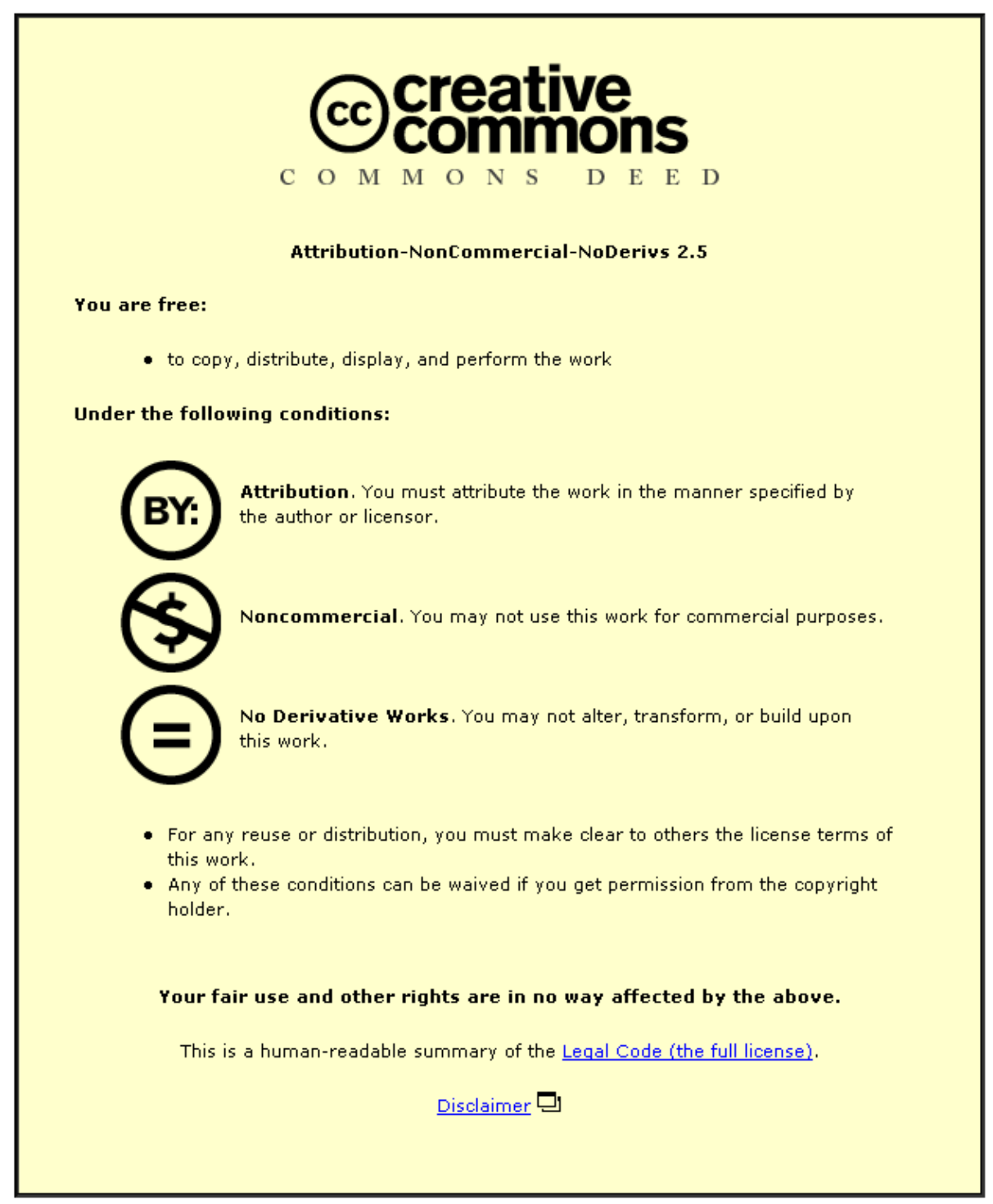

For the full text of this licence, please go to: http://creativecommons.org/licenses/by-nc-nd/2.5/ 


\section{Infection Outbreaks in Acute Hospitals: A Systems Approach}

\begin{tabular}{|c|l|}
\hline Journal: & Journal of Infection Prevention \\
\hline Manuscript ID: & Draft \\
\hline Manuscript Type: & Original Article \\
\hline Keyword: & $\begin{array}{l}\text { Health care ergonomics, Infection Prevention and Control, } \\
\text { Sociotechnical systems }\end{array}$ \\
& $\begin{array}{l}\text { This paper puts forward the case for applying a systems approach } \\
\text { to the analysis of hospital-based infection outbreaks. A major } \\
\text { advantage of the systems approach is that it affords insights into } \\
\text { how actions or occurrences at one system level (e.g., individual } \\
\text { error) collectively interact with team (e.g., leadership style) and } \\
\text { organisational (e.g., safety culture) levels of analysis. Most of the } \\
\text { research concerned with behavioural aspects of infection control } \\
\text { has focused on a single level of analysis (e.g., interventions to } \\
\text { improve hand washing). The infection outbreaks at the Maidstone } \\
\text { and Tunbridge Wells NHS Trust are used as a case study in order to } \\
\text { demonstrate the usefulness of the systems approach. The paper } \\
\text { further outlines the human and organisational issues raised by the } \\
\text { analysis and provides a means through which these aspects of } \\
\text { infection can be highlighted as part of a future research agenda. }\end{array}$ \\
\hline
\end{tabular}

\section{ScholarONE \\ Manuscript Central}


Infection Outbreaks in Acute Hospitals: A Systems Approach

\begin{abstract}
This paper puts forward the case for applying a systems approach to the analysis of hospital-based infection outbreaks. A major advantage of the systems approach is that it affords insights into how actions or occurrences at one system level (e.g., individual error) collectively interact with team (e.g., leadership style) and organisational (e.g., safety culture) levels of analysis. Most of the research concerned with behavioural aspects of infection control has focused on a single level of analysis (e.g., interventions to improve hand washing). The infection outbreaks at the Maidstone and Tunbridge Wells NHS Trust are used as a case study in order to demonstrate the usefulness of the systems approach. The paper further outlines the human and organisational issues raised by the analysis and provides a means through which these aspects of infection can be highlighted as part of a future research agenda.
\end{abstract}

\title{
Keywords
}

Health Care Ergonomics; Systems Analysis; Sociotechnical Systems; Healthcareassociated Infections; Acute Hospitals; Organisational Change

\section{Acknowledgements}

I would like to thank Mark Cole of Nottingham University for his advice and encouragement with this work. 


\section{Introduction}

Within the last few years the subject of hospital infection control has become the subject of much media attention (e.g., Guardian Newspaper, 2007; BBC Panorama, 2008). A number of high profile hospital outbreaks within the United Kingdom (UK) involving bacterium such as Clostridium difficile (C. diff.) and Methicillin-resistant Staphylococcus aureus (MRSA) and the number of mortalities resulting from these outbreaks, has made infection control into a central priority for the NHS and other health care systems worldwide (Allegranzi et al., 2007). Much of the debate so far has concentrated on improving hygiene within hospitals (e.g., hand washing). Very little research has been conducted on the wider behavioural, social and organisational factors that may also determine infection control outbreaks (Griffiths, Renz and Rafferty, 2008). The intention of the present study is to outline the potential of adopting a systems ergonomic perspective towards hospital-based infections.

\section{The systems approach and systems ergonomics}

Systems ergonomics, examines large-scale issues such as the analysis and improvement of work environments that involve social and technical ("sociotechnical") elements including organisational structures, policies and procedures. Likewise, the systems approach involves a detailed examination of how these factors interact with one another and how they are distributed across a range of system levels and interfaces (e.g., management, staff and individual levels). A number of different types of accidents, disasters and large-scale system failures have been analysed in the past, spanning a range of domains including transportation (e.g., the Paddington rail accident - SantosReyes and Beard, 2006; Wilson et al., 2007), nuclear power (e.g., the Chernobyl disaster - Reason, 1987, 2008) and patient safety (Vincent, 2006).

Hospitals represent good examples of complex large-scale sociotechnical systems since they involve a large diversity of professions spanning a range of roles and specialisms as well as technologies and artefacts ranging from the latest eHealth applications (e.g., electronic patient record systems) to more established physical design components (e.g., wards and buildings). Within systems ergonomics, a number of modelling frameworks exist (e.g., Vicente, 2006; Rasmussen, 1997) for understanding the dynamic interaction between levels within large-scale sociotechnical systems (Figure 1). 
Figure 1 about here

Vicente and Christoffersen (2006) have used the framework to identify the lessons learnt from the May 2000 outbreak of Escherichia coli (E. coli) which occurred in Walkerton, Canada. Their analysis used a graphical representation of the contributing factors that led up to the Walkerton outbreak. These ranged from decisions made at governmental levels (e.g., privatisation initiatives), the action of actors within the system (e.g., failures to take water samples), as well as equipment failures (e.g., shallow water wells). In order to demonstrate the value of applying the systems approach and these types of modelling frameworks to infection control, the paper focuses on a specific case study, namely the Maidstone and Tunbridge Wells NHS Trust outbreaks in the UK which occurred between 2005-2007 (Healthcare Commission (HC), 2007).

\section{The Clostridium difficile outbreaks in the Maidstone and Tunbridge Wells NHS Trust}

Background to the outbreaks and timeline

During the period between April 2004 and September 2006 an estimated 90 people died at the Maidstone and Tunbridge Wells NHS Trust as a result of becoming infected with the Clostridium difficile (C. diff.) bacteria (HC, 2007, p.5). Table 1 a timescale summarises the main events as they occurred at the Trust.

Table 1 about here 
Contributory factors leading up to the outbreaks

The Healthcare Commission report identified a number of factors that contributed to the outbreaks that occurred with the Trust. These can be summarised in terms of five main themes: the role played by external organisations; management of the trust; clinical management on the hospital wards; the role played by the infection control team; and, equipment and hygiene factors.

The role of external organisations

Within the report both the setting of government-led targets and financial pressures on NHS Trusts are mentioned as background, contributory factors that had an impact on the day-to-day operation of the Maidstone and Tunbridge Wells Trust. In particular, the report mentions the need for Trust board members and managers to meet targets for the use of beds. Higher bed occupancy meant that there was less time for the cleaning and a higher probability of transmission of infection between patients (HC, 2007, pp.69-70). The need to meet financial targets also placed pressure on the Trust to decrease spending in areas that impacted upon infection control such as financing for new buildings and isolation areas.

Infection control within the UK NHS is overseen by a number of bodies including the Health Protection Agency (HPA). The remit of the HPA is to provide advice and support to NHS, local authorities and other agencies with regard to public health issues. The creation of the HPA in April 2005 coincided with the first outbreak at the Trust. One part of the HPA, the health protection unit (HPU), was set up in order to support organisations in their management of infections. The report highlights that this caused some confusion within the Trust at the time of the outbreaks, as the expectation was that the HPU could give provide guidance covering the supervision and monitoring of infection control. The HPU did not have close involvement with the Trust and generally worked in a reactive way, responding to concerns as they arose (HC, 2007, p. 8). Similar problems were encountered within the much larger Strategic Health Authority (SHA) who are responsible for implementing government policy and fiscal control within regions of the UK.

Management of the Trust 
The report describes a catalogue of problems and failures associated with the management of the trust at the time of the outbreaks. In terms of clinical risks and incidents, management strategy in general "had been fragmentary and poorly understood" (HC, 2007, p. 77). The reports from an internal group set up within the Trust in order to analyse complaints, claims and incidents highlight, amongst others, the following issues: the unsatisfactory nature of some "escalation" areas (areas temporarily set up to deal with infected patients); the impact that the accident and emergency $(A \& E)$ target had on the quality of care; poor quality handover and transfer to wards from A\&E; concerns about staffing levels, and, bank staff managing wards on some shifts. The style of leadership within the Trust and the overall management culture were also criticised in the report. Many staff described the leadership of the chief executive as being "autocratic" or "dictatorial" (HC, 2007 p. 91). The report concluded that the person appointed as director of infection prevention and control had "no real understanding of the role at the outset" (HC, 2007, p. 5). Turnover of managers and directors was also high.

Finally, the trust's management of staffing was criticised heavily within the report in several places. In 2006/07 the number of nurse per bed was 1.52, the same number as in 2003/04 (HC, 2007, p. 82). Trust managers had not carried out a comprehensive review of staffing levels or a determination of minimum staffing levels.

Clinical management on the hospital wards

A review of the case notes of 50 patients who had died having had $C$. diff. found that in $80 \%$ of the cases, at least one element of the clinical management, or monitoring of $C$. diff at ward level was unsatisfactory (HC, 2007, p. 4). A number of elements were mentioned, including: infrequent reviews of patients by doctors; lack of systematic monitoring as to whether or not a patient was recovering from $C$. diff.; and, failure to change antibiotic treatment when a patient failed to respond to the initial treatment (HC, 2007, p. 4). Delays in starting treatment occurred on the wards, mostly because there was a delay in sending samples for analysis (HC, 1007, p. 33). There was also little evidence that once $C$. diff. had been diagnosed, that patients were monitored for severe signs of the infection (HC, 2007, p. 34). In other cases, it was clear that diagnoses were either not considered or had been missed. In $34 \%$ of the cases reviewed, medical records did not indicate that a regular review of $C$. diff had taken place (HC, 2007, p. 
38). The management of fluids and nutrition on the wards was also inconsistent. In $36 \%$ of the cases there was evidence of poor fluid management and in $34 \%$ nutritional needs had not been assessed or managed (HC, 2007, p. 38).

The infection control team

The role played by the infection control team within the trust was a complex one and one made difficult by problems relating to accountability, the amount of resources available to them and their ability to function as a team. The arrangements for accountability were not clear (HC, 2007, p. 54) and it was not clear who was responsible for the team. Infection control nurses were accountable to the director of nursing, however, the pathology manager held the budget for these nurses, but did not consider that he had any management responsibly for infection control. Not until September 2006 did the trust take steps to clarify the management of the team (HC, 2007, p. 51).

\section{Equipment and hygiene}

Hygiene practices within the trust and the state of hospital buildings contributed a great deal to the outbreaks. Wards, bathrooms and commodes were not clean and patients had in some cases to share equipment (e.g., Zimmer frames) which were not cleaned before use (HC, 2007, p. 4). The infection control team were keen to isolate patients once they had been identified as $C$. diff. cases, however the scarcity of side rooms made this difficult. As a result many patients before and after the outbreaks were kept on open wards. The design of buildings and their age meant that many wards did not have sufficient space for storage or the provision of hand basins in utility rooms. The buildings in the trust were generally old or in a poor state of repair and when they were first opened di not have adequate cleaning and laundry services (HC, 2007, p. 6).

\section{Analysing the outbreaks using the systems approach}

The outbreaks which occurred within the Maidstone and Tunbridge Wells Trust represent the combined impact of a complex set of factors extending over several years. In common with most examples of accidents, disasters or large-scale adverse events, the outbreaks are best interpreted as arising through the combination of a number of interrelated systemic factors and influences (Turner, 1978; Reason, 2008). Figure 2 attempts to use some of the elements of the systems ergonomic frameworks described 
Figure 2 about here

\section{Government, regulatory bodies and trust governance}

At the very highest level of the system it is difficult to pinpoint exactly the role played by government-set targets as a discrete factor leading to the outbreaks. Targets placed many individuals, particularly those at trust board and management levels under a great deal of pressure. This pressure in itself may have led them to make poor decisions, and in some cases to prioritise bed occupancy rates at the expense of the risk of an infection outbreak. Previous research on the influence that targets have on management decision-making in health care tends to be equivocal. Bean and Hood (2006) for example, show that the impact of satisfying a specific target (e.g., hospital waiting times) has not been analysed in terms of how this influences other related services (e.g., quality of care). Others have suggested that health care targets represent: "tin openers rather than dials ... they do not give answers but prompt further investigation and inquiry, and by themselves provide an incomplete and inaccurate answer" (Carter, Klein and Day, 1995). Within the trust it is likely that targets exerted considerable pressure on the system as a whole and this pressure filtered down various levels of the system. It is possible that the drive to comply with these targets increased the likelihood of an adverse event or set of events taking place at some stage within the trust.

Poor communication, confusion of responsibilities and accountabilities between and within the various regulatory bodies delayed the time in which they could react to the outbreaks. A separate report by the Healthcare Commission (2008) examined the underlying causes of serious failures in NHS health care providers and identified large- 
scale organisational processes such as mergers and poor change management procedures as common factors. Within the wider literature on large-scale accidents and disasters (e.g., Perrow, 1999, 2007) the nature of organisational linkages and structures are also widely acknowledged to be significant explanatory factors.

\section{Hospital management}

Within the hospital the actions of senior managers were identified as significantly contributing to the failure to prevent and deal with the outbreaks. The link between management, human resource management (HRM) practices and work performance outcomes has been investigated in detail in the last few years. Wood and Wall (2002) for example, reviewed the evidence that suggests there is a link between highinvolvement HRM practices and employee productivity. High involvement HRM practices typically include empowering employees to make their own decisions and the presence of self-managed teams. The review showed that there these types of practices in organisations do tend to increase levels of employee productivity. Similar effects have been shown between HRM practices and measurements of safety outcomes (e.g., number of adverse events). In general, there is strong evidence to suggest that aspects of management behaviour partially shape and determine the culture of safety within organisations (e.g., Zohar, 2000). Within health care specifically, West et al. (2002) carried out a large-scale survey of the relationship between HRM practices and general in-hospital mortality. The survey showed some aspects of high involvement HRM were associated with lower mortality rates after adjustment for patient and hospital characteristics.

Aside from the way in which senior managers behaved at the trust, the questions still remains as to why they ignored, or at least failed to realise the seriousness of the outbreaks and their consequences. Many of the managers interviewed in the original Healthcare Commission report reported that they were aware of how serious the situation had become within the trust, but were powerless to do anything about it. One possible explanation is what Vaughan (1996) in her study of the Challenger shuttle disaster termed the "normalization of deviance", namely that managers over time began to accept and take for granted the level of infection risk within the Trust. Only after the level of risk built up to a point where it could not be controlled, did they begin to realise the gravity of the situation. 
Clinical management and equipment and buildings

Understaffing and general lack of resources together played a part in the outbreaks. Staffing ratios and levels of staff morale almost certainly contributed to the problem of containing the spread of infection on the wards. In general, the research literature provides some evidence that lower levels of staffing increase the likelihood of infections occurring. Hugonnet et al. (2004) (cited in Griffiths et al., 2008) examined the numbers of nursing staff and staff downsizing relative to infection levels. The researchers found an inverse relationship between staff downsizing and the rate of hospital-based infection. Curiously, little research has been conducted on the impact of job satisfaction/morale on hospital infection levels, however, work in other domains (e.g., manufacturing and service industries) suggests that lower levels of satisfaction are clearly linked to lower levels of job performance (e.g., Parker, 2007).

It might be conjectured that the behaviour of clinicians and other health care professionals within the trust shares similarities with those of senior managers and trust board managers. Many individuals at ward level were aware of the levels of poor hygiene and inadequate patient monitoring practices, but saw no way to improve the situation. Weick and Sutcliffe (2003) analysed data from the Bristol Royal Infirmary Report (Department of Health, 2001) and concluded that hospital staff became locked into particular lines of action or behaviour where they "search for confirmation that they are doing what they should be doing" (p. 73). These so-called "cultures of entrapment" inhibit an organisation's ability to break out of patterns of behaviour that over time can lead to adverse outcomes. In the case of the trust they may provide some means with which to explain shared boundary spanning behaviours between levels within the hospital subsystem (figure 1).

\section{Ways forward and conclusions}

The analysis presented in the paper has shown that there are advantages in analysing hospital-based infection outbreaks from a system's perspective. Many of the issues that have been discussed have not been researched in much depth within infection control, particularly organisational and managerial behaviour. The paper has only touched upon some of the behavioural issues involved with a system as complex as hospital-based 
healthcare. Much more research needs to be carried out, the aim being that the outcomes from this can be translated into practice. We are currently in danger of only seeing one part a much larger picture. Adopting a systems approach is one step towards filling in the missing details, particular as they relate to causal relationships that may exists between system levels such as the interaction between management styles, aspects of hospital design and individual behaviour (e.g., hand washing), and outcomes (e.g., infection rates).

2878 words 


\section{References}

Allegranzi B, Storr J, Dziekan G, Leotsakos A, Donaldson L and Pittet D. (2007) The first global patient safety challenge "Clean Care is Safer Care" from launch to current progress and achievements. Journal of Hospital Infection, 65 (supplement 2): 15.

BBC Panorama (2008), How Safe is Your Hospital? (Broadcast on $27^{\text {th }}$ April, 2008), (available at:

http://www.bbc.co.uk/mediaselector/check/player/nol/newsid_7370000/newsid_7371 100? redirect=7371116.stm\&news $=1 \&$ nbram $=1 \&$ nbwm $=1 \&$ bbram $=1 \&$ bbwm $=1$ accessed $28^{\text {th }}$ April, 2008)

Bean G and Hood C. (2006), Have targets improved performance in the English NHS? British Medical Journal, (32), 419-422.

Carter M, Klein R and Day P. (1995), How Organisations Measure Success: The use of Performance Indicators in Government. Routledge: London.

Department of Health (2001), Learning from Bristol. The Report of the Public Inquiry into children's heart surgery at the Bristol Royal Infirmary1984-1995. The Stationary Office: London

Griffiths P, Renz A and Rafferty AM. (2008), The impact of organisation and management factors on infection control in hospitals: a scoping review. Kings College, London.

\section{(http://www.kcl.ac.uk/content/1/c6/04/08/39/Infectioncontrolreport.pdf,} (accessed $15^{\text {th }}$ September, 2008).

The Guardian (2007), Deadly superbug infections widespread in UK hospitals, says expert. The Guardian newspaper, October $11^{\text {th }} 2007$.

Healthcare Commission (2007), Investigation into outbreaks of Clostridium difficile at Maidstone and Tunbridge Wells NHS Trust. (http://www.healthcarecommission.org.uk/_db/_documents/Maidstone_and_Tunbridg e_Wells_investigation_report_Oct_2007.pdf 
(accessed $8^{\text {th }}$ April 2008).

Healthcare Commission (2008) Learning from Investigations

(http://www.healthcarecommission.org.uk/_db/_documents/Learning_from_investigat ions.pdf (accessed 17th September 2008).

Huggonet S, Harbath S, Sax H, Duncan RA and Pittet D. (2004), Nursing resources: a major determinant of nosocomial infection? Current Opinion in Infections Diseases, (17), 4, 329.

Parker SK. (2007). "That is my job”: How employees' role orientation affects their job performance, Human Relations, 60 (3), 403-434.

Perrow C. (1999), Normal Accidents. Princeton University Press: Princeton, New Jersey.

Perrow C. (2007), The Next Catastrophe. Princeton University Press: Princeton, New Jersey.

Rasmussen J. (1997), Risk management in a dynamic society: a modelling problem. Safety Science, 27, 183-213.

Reason J. (1987), The Chernobyl errors. Bulletin of the British Psychological Society, 40, 201-206.

Reason J. (2008), The Human Contribution - Unsafe Acts, Accidents and Heroic Discoveries. Ashgate: London.

Santos-Reyes, J and Beard, AN (2006), A systemic analysis of the Paddington rail accident. Proceedings of the Institute of Mechanical Engineering, Part F, 220, 121151.

Turner BA. (1978), Man-Made Disasters. Wykeham Publications: London. 
Vaughan D. (1996), The Challenger Launch Decision: Risky Technology, Culture and Deviance at NASA. Chicago University Press: Chicago.

Vicente KJ. (2006), The Human Factor. Routledge: London.

Vicente KJ and Christoffersen K. (2006), The Walkerton E. Coli outbreak: a test of Rasmussen's framework for risk management in a dynamic society. Theoretical Issues in Ergonomics Science, (7), 2, 93-112.

Vincent C (2006), Patient Safety. Churchill-Livingstone: Edinburgh.

Weick KE and Sutcliffe KM. (2003), Hospitals as cultures of re-enactment: a reanalysis of the Bristol Royal Infirmary. California Management Review, (45), 2, 73 84.

West MA, Borrill C, Dawson J, Scully J, Carter M, Anelay S, Patterson M and Waring J. (2002), The link between the management of employees and patient mortality in acute hospitals. International Journal of Human Resource Management, $13,8,1299-1310$.

Wilson JR, Farrington-Darby T, Bye R and Hockey GRJ. (2007), The railway as a socio-technical system: Human factors at the heart of successful rail engineering. Proceedings of the Institute of Mechanical Engineering, Part F, 221, 101-125.

Wood S and Wall TD. (2002), Human resource management and business performance. In: Warr, PB (Ed.), Psychology at Work ( $5^{\text {th }}$ Edition). Penguin Books: Harmondsworth.

Zohar D. (2000), A group-level model of safety climate: Testing the effect of group climate on microaccidents in manufacturing jobs. Journal of Applied Psychology, 85, 587-96. 
Table 1: Summary timeline of infection outbreaks

\begin{tabular}{ll}
\hline Time Period & Trust established following merger between two other \\
\hline April 2000 & $\begin{array}{l}\text { local NHS Trusts } \\
\text { High turnover of senior managers and period of } \\
\text { organizational stability }\end{array}$ \\
October 2005 - & $\begin{array}{l}\text { More than 500 patients developed the infection, 60 patients } \\
\text { September 2006 }\end{array}$ \\
Beftimated to have died due to $C$. difficile infection. \\
Trust has a high level of infection with C. difficile but no \\
one in the trust or local health authority was aware of this \\
Number of patients infected doubles. Approximately 150 \\
patients affected, a number of whom died as a result of the \\
infection. (first outbreak) \\
258 patients in total affected \\
April - Sept. 2006
\end{tabular}




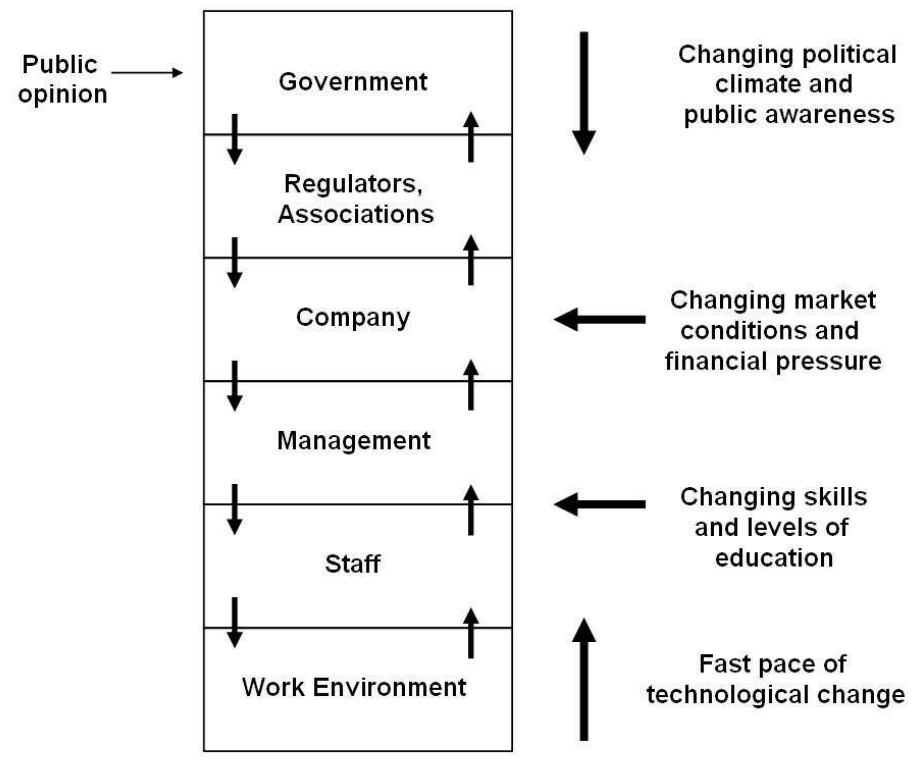

$338 \times 270 \mathrm{~mm}(96 \times 96 \mathrm{DPI})$ 


\title{
Infection Outbreaks in Acute Hospitals: A Systems Approach
}

\begin{abstract}
This paper puts forward the case for applying a systems approach to the analysis of hospital-based infection outbreaks. A major advantage of the systems approach is that it affords insights into how actions or occurrences at one system level (e.g., individual error) collectively interact with team (e.g., leadership style) and organisational (e.g., safety culture) levels of analysis. Most of the research concerned with behavioural aspects of infection control has focused on a single level of analysis (e.g., interventions to improve hand washing). The infection outbreaks at the Maidstone and Tunbridge Wells NHS Trust are used as a case study in order to demonstrate the usefulness of the systems approach. The paper further outlines the human and organisational issues raised by the analysis and provides a means through which these aspects of infection can be highlighted as part of a future research agenda. within infection prevention using the systems approach (Deleted).
\end{abstract}

\section{Keywords}

Health Care Ergonomics; Systems Analysis; Sociotechnical Systems; Healthcareassociated Infections; Acute Hospitals; Organisational Change

\section{Acknowledgements}

I would like to thank Mark Cole of Nottingham University for his advice and encouragement with this work. 


\section{Introduction}

Within the last few years the subject of hospital infection control has become the subject of much media attention (e.g., Guardian Newspaper, 2007; BBC Panorama, 2008). A number of high profile hospital outbreaks within the United Kingdom (UK) (New text) involving bacterium such as Clostridium difficile (C. diff.) and Methicillinresistant Staphylococcus aureus (MRSA) (New text) and the number of mortalities resulting from these outbreaks, has made infection control into a central priority for the NHS and other health care systems worldwide (Allegranzi et al., 2007). Much of the debate so far has concentrated on improving hygiene within hospitals (e.g., hand washing). Very little research has been conducted on the wider behavioural, social and organisational factors that may also determine infection control outbreaks (Griffiths, Renz and Rafferty, 2008). (Sentence broken into two). The intention of the present study is to outline the potential of adopting a systems ergonomic perspective towards hospital-based infections.

The intention of the present study is to outline the potential of adopting a systems ergonomic perspective towards hospital-based infections. Systems ergonomics, examines large-scale issues such as the analysis and improvement of work environments that involve social and technical ("sociotechnical") elements including organisational structures, policies and procedures. This type of work can be used to understand the complex interplay of factors that contribute to accidents and disasters (e.g., Railway and aviation accidents - Wilson et al., 2007; Reason, 2008), as well as provide recommendations aimed at minimising these factors. In order to demonstrate the value of such an approach the paper focuses on a specific case study, namely the Maidstone and Tunbridge Wells NHS Trust outbreaks which occurred between 20052007 (Healthcare Commission, 2007). (Deleted)

\section{The systems approach and systems ergonomics (This section has been enlarged and re-written)}

Systems ergonomics, examines large-scale issues such as the analysis and improvement of work environments that involve social and technical ("sociotechnical") elements including organisational structures, policies and procedures. Likewise, the systems approach involves a detailed examination of how these factors interact with one another 
Figure 1 about here

Vicente and Christoffersen (2006) have used the modelling (Deleted) framework to identify the lessons learnt from the May 2000 outbreak of Escherichia coli (E. coli) (New Text) which occurred in Walkerton, Canada. Their analysis used a graphical representation of the contributing factors that led up to the Walkerton outbreak. These ranged from decisions made at governmental levels (e.g., privatisation initiatives), the action of actors within the system (e.g., failures to take water samples), as well as equipment failures (e.g., shallow water wells). In order to demonstrate the value of such an approach the paper focuses on a specific case study, namely the Maidstone and Tunbridge Wells NHS Trust outbreaks in the UK which occurred between 2005-2007 (Healthcare Commission, 2007). (Deleted) In order to demonstrate the value of applying the systems approach and these types of modelling frameworks to infection control, the paper focuses on a specific case study, namely the Maidstone and 
Tunbridge Wells NHS Trust outbreaks in the UK which occurred between 2005-2007 (Healthcare Commission (HC), 2007). (New text) The next section outlines the main events and contributory factors leading up to the outbreaks. These are used to suggest ways in which the outbreaks could be analysed in more detail, and modelled using a systems ergonomic approach. (deleted)

\section{The Clostridium difficile outbreaks in the Maidstone and Tunbridge Wells NHS Trust}

Background to the outbreaks and timeline

During the period between April 2004 and September 2006 an estimated 90 people died at the Maidstone and Tunbridge Wells NHS Trust as a result of becoming infected with the Clostridium difficile (C. diff.) bacteria (Healthcare Commission, (Deleted), HC (New text) 2007, p.5). Table 1 a timescale summarises the main events as they occurred at the Trust.

Table 1 about here

Contributory factors leading up to the outbreaks

The Healthcare Commission (2007, HC, 2007) report identified a number of factors that contributed to the outbreaks that occurred with the Trust. These can be summarised in terms of five main themes: the role played by external organisations; management of the trust; clinical management on the hospital wards; the role played by the infection control team; and, equipment and hygiene factors.

The role of external organisations

Within the report both the setting of government-led targets and financial pressures on NHS Trusts are mentioned as background, contributory factors that had an impact on the day-to-day operation of the Maidstone and Tunbridge Wells Trust. In particular, the 
report mentions the need for Trust board members and managers to meet targets for the use of beds. Higher bed occupancy meant that there was less time for the cleaning and a higher probability of transmission of infection between patients (HC, 2007, pp.69-70). The need to meet financial targets such as spending on equipment and buildings (Deleted) also placed pressure on the Trust to cut back (Deleted) decrease spending (New text) in areas that impacted upon infection control such as financing for new buildings and isolation areas.

Infection control within the UK NHS is overseen (New text and deletion) by a number of bodies including the Health Protection Agency (HPA). The remit of the HPA is to provide advice and support to NHS, local authorities and other agencies with regard to public health issues. The creation of the HPA in April 2005 coincided with the first outbreak at the Trust. One part of the HPA, the health protection unit (HPU), was set up in order to support organisations in their management of infections. The report highlights that this caused some confusion within the Trust at the time of the outbreaks, as the expectation was that the HPU could give provide guidance covering the supervision and monitoring of infection control. The HPU did not have close involvement with the Trust and generally worked in a reactive way, responding to concerns as they arose (HC, 2007, p. 8). Similar problems were encountered within the much larger Strategic Health Authority (SHA) who are responsible for implementing government policy and fiscal control within regions of the UK.

\section{Management of the Trust}

The report describes a catalogue of problems and failures associated with the management of the trust at the time of the outbreaks. In terms of clinical risks and incidents, management strategy in general "had been fragmentary and poorly understood" (HC, 2007, p. 77). The reports from an internal group set up within the Trust in order to analyse complaints, claims and incidents highlight, amongst others, the following issues: the unsatisfactory nature of some "escalation" areas (areas temporarily set up to deal with infected patients); the impact that the accident and emergency $(\mathrm{A} \& \mathrm{E})$ target had on the quality of care; poor quality handover and transfer to wards from A\&E; concerns about staffing levels, and, bank staff managing wards on some shifts. The style of leadership within the Trust and the overall management culture were also criticised in the report. Many staff described the leadership of the chief executive 
as being "autocratic" or "dictatorial" (HC, 2007 p. 91). The report concluded that the person appointed as director of infection prevention and control had "no real understanding of the role at the outset" (HC, 2007, p. 5). Turnover of managers and directors was also high.

Finally, the trust's management of staffing was criticised heavily within the report in several places. The number of nurses working on wards had fallen since the period 2002/03. and at the same time the number of beds had also reduced. (Deleted) In 2006/07 the number of nurse per bed was 1.52, the same number as in 2003/04 (HC, 2007, p. 82). Trust managers had not carried out a comprehensive review of staffing levels or a determination of minimum staffing levels.

Clinical management on the hospital wards

A review of the case notes of 50 patients who had died having had $C$. diff. found that in $80 \%$ of the cases, at least one element of the clinical management, or monitoring of $C$. diff at ward level was unsatisfactory (HC, 2007, p. 4). A number of elements were mentioned, including: infrequent reviews of patients by doctors; lack of systematic monitoring as to whether or not a patient was recovering from $C$. diff.; and, failure to change antibiotic treatment when a patient failed to respond to the initial treatment (HC, 2007, p. 4). Delays in starting treatment occurred on the wards, mostly because there was a delay in sending samples for analysis (HC, 1007, p. 33). There was also little evidence that once $C$. diff. had been diagnosed, that patients were monitored for severe signs of the infection (HC, 2007, p. 34). In other cases, it was clear that diagnoses were either not considered or had been missed. In $34 \%$ of the cases reviewed, medical records did not indicate that a regular review of $C$. diff had taken place (HC, 2007, p. 38). The management of fluids and nutrition on the wards was also inconsistent. In $36 \%$ of the cases there was evidence of poor fluid management and in $34 \%$ nutritional needs had not been assessed or managed (HC, 2007, p. 38).

The infection control team

The role played by the infection control team within the trust was a complex one and one made difficult by problems relating to accountability, the amount of resources available to them and their ability to function as a team. The arrangements for accountability were not clear (HC, 2007, p. 54) and it was not clear who was 
responsible for the team. Infection control nurses were accountable to the director of nursing, however, the pathology manager held the budget for these nurses, but did not consider that he had any management responsibly for infection control. Not until September 2006 did the trust take steps to clarify the management of the team (HC, 2007, p. 51).

\section{Equipment and hygiene}

Hygiene practices within the trust and the state of hospital buildings contributed a great deal to the outbreaks. Wards, bathrooms and commodes were not clean and patients had in some cases to share equipment (e.g., Zimmer frames) which were not cleaned before use (HC, 2007, p. 4). The infection control team were keen to isolate patients once they had been identified as $C$. diff. cases, however the scarcity of side rooms made this difficult. As a result many patients before and after the outbreaks were kept on open wards. The design of buildings and their age meant that many wards did not have sufficient space for storage or the provision of hand basins in utility rooms. The buildings in the trust were generally old or in a poor state of repair and when they were first opened di not have adequate cleaning and laundry services (HC, 2007, p. 6).

\section{Analysing the outbreaks using the systems approach}

The outbreaks which occurred within the Maidstone and Tunbridge Wells Trust represent the combined impact of a complex set of factors extending over several years. In common with most examples of accidents, disasters or large-scale adverse events, the outbreaks are best interpreted as arising through the combination of a number of interrelated systemic factors and influences (Turner, 1978; Reason, 2008). Figure 2 attempts to use some of the elements of the systems ergonomic frameworks described earlier in the paper (figure 1) in order to further analyse the outbreaks. In order to illustrate the framework as it applies to the outbreaks, a small sample of the contributory factors are used to link together some of the system components. 
Figure 2 about here

Government, regulatory bodies and trust governance

At the very highest level of the system it is difficult to pinpoint exactly the role played by government-set targets as a discrete factor leading to the outbreaks. Targets placed many individuals, particularly those at trust board and management levels under a great deal of pressure. This pressure in itself may have led them to make poor decisions, and in some cases to prioritise bed occupancy rates at the expense of the risk of an infection outbreak. Previous research on the influence that targets have on management decision-making in health care tends to be equivocal. Bean and Hood (2006) for example, show that the impact of satisfying a specific target (e.g., hospital waiting times) has not been analysed in terms of how this influences other related services (e.g., quality of care). Others have suggested that health care targets represent: "tin openers rather than dials ... they do not give answers but prompt further investigation and inquiry, and by themselves provide an incomplete and inaccurate answer" (Carter, Klein and Day, 1995). Within the trust it is likely that targets exerted considerable pressure on the system as a whole and this pressure filtered down various levels of the system. It is possible that the drive to comply with these targets increased the likelihood of an adverse event or set of events taking place at some stage within the trust.

Poor communication, confusion of responsibilities and accountabilities between and within the various regulatory bodies delayed the time in which they could react to the outbreaks. A separate report by the Healthcare Commission (2008) examined the underlying causes of serious failures in NHS health care providers and identified largescale organisational processes such as mergers and poor change management procedures as common factors. Within the wider literature on large-scale accidents and disasters (e.g., Perrow, 1999, 2007 (New reference) the nature of organisational linkages and structures are also widely acknowledged to be significant explanatory factors. 
Hospital management

Within the hospital the actions of senior managers were identified as significantly contributing to the failure to prevent and deal with the outbreaks. The link between management, human resource management (HRM) practices and work performance outcomes has been investigated in detail in the last few years. Wood and Wall (2002) for example, reviewed the evidence that suggests there is a link between highinvolvement HRM practices and employee productivity. High involvement HRM practices typically include empowering employees to make their own decisions and the presence of self-managed teams. The review showed that there these types of practices in organisations do tend to increase levels of employee productivity. Similar effects have been shown between HRM practices and measurements of safety outcomes (e.g., number of adverse events). In general, there is strong evidence to suggest that aspects of management behaviour partially shape and determine the culture of safety within organisations (e.g., Zohar, 2000). Within health care specifically, West et al. (2002) carried out a large-scale survey of the relationship between HRM practices and general in-hospital mortality. The survey showed some aspects of high involvement HRM were associated with lower mortality rates after adjustment for patient and hospital characteristics.

Aside from the way in which senior managers behaved at the trust, the questions still remains as to why they ignored, or at least failed to realise the seriousness of the outbreaks and their consequences. Many of the managers interviewed in the original Healthcare Commission report reported that they were aware of how serious the situation had become within the trust, but were powerless to do anything about it. One possible explanation is what Vaughan (1996) in her study of the Challenger shuttle disaster termed the "normalization of deviance", namely that managers over time began to accept and take for granted the level of infection risk within the Trust. Only after the level of risk built up to a point where it could not be controlled, did they begin to realise the gravity of the situation.

Clinical management and equipment and buildings

Understaffing and general lack of resources together played a part in the outbreaks. Staffing ratios and levels of staff morale almost certainly contributed to the problem of 
containing the spread of infection on the wards. In general, the research literature provides some evidence that lower levels of staffing increase the likelihood of infections occurring. Hugonnet et al. (2004) (cited in Griffiths et al., 2008) examined the numbers of nursing staff and staff downsizing relative to infection levels. The researchers found an inverse relationship between staff downsizing and the rate of hospital-based infection. Curiously, little research has been conducted on the impact of job satisfaction/morale on hospital infection levels, however, work in other domains (e.g., manufacturing and service industries) suggests that lower levels of satisfaction are clearly linked to lower levels of job performance (e.g., Parker, 2007).

It might be conjectured that the behaviour of clinicians and other health care professionals within the trust shares similarities with those of senior managers and trust board managers. Many individuals at ward level were aware of the levels of poor hygiene and inadequate patient monitoring practices, but saw no way to improve the situation. Weick and Sutcliffe (2003) analysed data from the Bristol Royal Infirmary Report (Department of Health, 2001) and concluded that hospital staff became locked into particular lines of action or behaviour where they "search for confirmation that they are doing what they should be doing" (p. 73). These so-called "cultures of entrapment" inhibit an organisation's ability to break out of patterns of behaviour that over time can lead to adverse outcomes. In the case of the trust they may provide some means with which to explain shared boundary spanning behaviours between levels within the hospital subsystem (figure 1).

\section{Ways forward and conclusions}

The analysis presented in the paper has shown that there are advantages in analysing hospital-based infection outbreaks from a system's perspective. Many of the issues that have been discussed have not been researched in much depth within infection control, particularly organisational and managerial behaviour. The paper has only touched upon some of the behavioural issues involved with a system as complex as hospital-based healthcare. Much more research needs to be carried out, the aim being that the outcomes from this can be translated into practice. We are currently in danger of only seeing one part a much larger picture. Adopting a systems approach is one step towards filling in the missing details, particular as they relate to causal relationships that may exists between system levels such as the interaction between management styles, 
aspects of hospital design and individual behaviour (e.g., hand washing), and outcomes (e.g., infection rates).

\section{New word count 2878 words}




\section{References}

Allegranzi B, Storr J, Dziekan G, Leotsakos A, Donaldson L and Pittet D. (2007) The first global patient safety challenge "Clean Care is Safer Care" from launch to current progress and achievements. Journal of Hospital Infection, 65 (supplement 2): 15.

BBC Panorama (2008), How Safe is Your Hospital? (Broadcast on $27^{\text {th }}$ April, 2008), (available at:

http://www.bbc.co.uk/mediaselector/check/player/nol/newsid_7370000/newsid_7371 100 ?redirect=7371116.stm\&news=1\&nbram=1\&nbwm=1\&bbram=1\&bbwm=1 accessed $28^{\text {th }}$ April, 2008)

Bean G and Hood C. (2006), Have targets improved performance in the English NHS? British Medical Journal, (32), 419-422.

Carter M, Klein R and Day P. (1995), How Organisations Measure Success: The use of Performance Indicators in Government. Routledge: London.

Department of Health (2001), Learning from Bristol. The Report of the Public Inquiry into children's heart surgery at the Bristol Royal Infirmary1984-1995. The Stationary Office: London

Griffiths P, Renz A and Rafferty AM. (2008), The impact of organisation and management factors on infection control in hospitals: a scoping review. Kings College, London.

(http://www.kcl.ac.uk/content/1/c6/04/08/39/Infectioncontrolreport.pdf, (accessed $15^{\text {th }}$ September, 2008).

The Guardian (2007), Deadly superbug infections widespread in UK hospitals, says expert. The Guardian newspaper, October $11^{\text {th }} 2007$.

Healthcare Commission (2007), Investigation into outbreaks of Clostridium difficile at Maidstone and Tunbridge Wells NHS Trust.

(http://www.healthcarecommission.org.uk/_db/_documents/Maidstone_and_Tunbridg e_Wells_investigation_report_Oct_2007.pdf 
(accessed $8^{\text {th }}$ April 2008).

Healthcare Commission (2008) Learning from Investigations

(http://www.healthcarecommission.org.uk/_db/_documents/Learning_from_investigat ions.pdf (accessed 17th September 2008).

Huggonet S, Harbath S, Sax H, Duncan RA and Pittet D. (2004), Nursing resources: a major determinant of nosocomial infection? Current Opinion in Infections Diseases, (17), 4, 329.

Parker SK. (2007). "That is my job”: How employees' role orientation affects their job performance, Human Relations, 60 (3), 403-434.

Perrow C. (1999), Normal Accidents. Princeton University Press: Princeton, New Jersey.

Perrow C. (2007), The Next Catastrophe. Princeton University Press: Princeton, New Jersey.

Rasmussen J. (1997), Risk management in a dynamic society: a modelling problem. Safety Science, 27, 183-213.

Reason J. (1987), The Chernobyl errors. Bulletin of the British Psychological Society, 40, 201-206. (New reference)

Reason J. (2008), The Human Contribution - Unsafe Acts, Accidents and Heroic Discoveries. Ashgate: London.

Santos-Reyes, J and Beard, AN (2006), A systemic analysis of the Paddington rail accident. Proceedings of the Institute of Mechanical Engineering, Part F, 220, 121151. (New reference)

Turner BA. (1978), Man-Made Disasters. Wykeham Publications: London. 
Vaughan D. (1996), The Challenger Launch Decision: Risky Technology, Culture and Deviance at NASA. Chicago University Press: Chicago.

Vicente KJ. (2006), The Human Factor. Routledge: London.

Vicente KJ and Christoffersen K. (2006), The Walkerton E. Coli outbreak: a test of Rasmussen's framework for risk management in a dynamic society. Theoretical Issues in Ergonomics Science, (7), 2, 93-112.

Vincent C (2006), Patient Safety. Churchill-Livingstone: Edinburgh. (New reference)

Weick KE and Sutcliffe KM. (2003), Hospitals as cultures of re-enactment: a reanalysis of the Bristol Royal Infirmary. California Management Review, (45), 2, 73 84.

West MA, Borrill C, Dawson J, Scully J, Carter M, Anelay S, Patterson M and Waring J. (2002), The link between the management of employees and patient mortality in acute hospitals. International Journal of Human Resource Management, $13,8,1299-1310$.

Wilson JR, Farrington-Darby T, Bye R and Hockey GRJ. (2007), The railway as a socio-technical system: Human factors at the heart of successful rail engineering. Proceedings of the Institute of Mechanical Engineering, Part F, 221, 101-125. (Correction).

Wood S and Wall TD. (2002), Human resource management and business performance. In: Warr, PB (Ed.), Psychology at Work (5 $5^{\text {th }}$ Edition). Penguin Books: Harmondsworth (Correction).

Zohar D. (2000), A group-level model of safety climate: Testing the effect of group climate on microaccidents in manufacturing jobs. Journal of Applied Psychology, 85, 587-96. 